\title{
AVALIAÇÃO DA EFICIÊNCIA ENERGÉTICA DO TRIBUNAL DE CONTAS DO PARANÁ, SEDIADO EM CURITIBA
}

\section{Evaluation of the Energy Efficiency of The Court of Auditors of Paraná, in Curitiba}

\section{Evaluación de Eficiencia Energética del Tribunal de Cuentas de} Paraná, Situado en Curitiba

\author{
MORO, Jeanne ${ }^{1}$ \\ CORREA, Pablo Cesar Bassani² \\ KRÜGER, Eduardo ${ }^{3}$ \\ 1Programa de Pós-graduação em Engenharia Civil - PPGEC, Universidade Tecnológica Federal do Paraná, Paraná, Brasil. \\ jeannemoro@gmail.com \\ ORCID ID: 0000-0003-3441-7501 \\ 2 Programa de Pós-graduação em Engenharia Civil - PPGEC, Universidade Tecnológica Federal do Paraná, Paraná, Brasil. \\ pablo.bcorrea@hotmail.com \\ ORCID ID: 0000-0001-8534-5769 \\ 3 Programa de Pós-graduação em Engenharia Civil - PPGEC, Universidade Tecnológica Federal do Paraná, Paraná, Brasil. \\ ekruger@utfpr.edu.br \\ ORCID ID: 0000-0003-2895-5530
}




\title{
RESUMO
}

A procura por maior eficiência energética no uso da eletricidade trouxe inúmeras iniciativas louváveis, no Brasil sob responsabilidade maior do Procel, com campanhas de conscientização dos usuários, pela etiquetagem de aparelhos eletrodomésticos até o panorama atual de certificação de edificações. $O$ presente estudo tem como objetivo principal avaliar o nível de eficiência energética por meio dos Requisitos Técnicos da Qualidade do Nível de Eficiência Energética para Edifícios Comerciais, de Serviços e Públicos (RTQ-C/Procel) do Tribunal de Contas (TC), parte do patrimônio histórico do Estado do Paraná, localizado no Centro Cívico de Curitiba. TC é composto de dois edifícios construídos e um terceiro edifício em projeto: o Edifício Sede, o Edifício Anexo e a Ampliação do Edifício Anexo. No Edifício Sede, foram analisados indicadores de possível economia energética resultante da melhoria dos sistemas de iluminação (natural e artificial). Na ampliação do Edifício Anexo, avaliou-se a aplicabilidade do sistema de sombreamento de fachadas denominado tela tensionada. Comprovou-se que os edifícios existentes apresentam grande potencial de economia energética em sistemas de iluminação e que, ao se aprimorarem os dispositivos de sombreamento da fachada no projeto de ampliação do Edifício Anexo, podem ser alcançados maiores níveis de eficiência energética no quesito envoltória.

Palavras chave: Sistemas de sombreamento de fachadas; RTQ-C; eficiência energética; sistemas de iluminação; sustentabilidade

\begin{abstract}
The search for higher energy efficiency in electricity has brought about several worth-mentioning initiatives, in Brazil supported by Procel, with a change in users' behaviour and conscientization, the labeling of household items including the current struggle towards the rating of buildings in terms of energy efficiency. The present paper is aimed at the evaluation of energy efficiency levels by means of the Brazilian standard "Requisitos Técnicos da Qualidade do Nível de Eficiência Energética para Edifícios Comerciais, de Serviços e Públicos" (RTQ-C/Procel) of the Tribunal de Contas (TC), which is part of the heritage of State Paraná and is located at the Civic Center of Curitiba. The TC is comprised of two buildings: Edifício Sede and Edifício Anexo; a third building is under planning. In Edificio Sede, potential energy saving indicators have been analyzed for the improvement of lighting systems (daylight and artificial lighting). In the extension of Edificio Anexo, the applicability of the facade shading elements was evaluated. Outcomes suggest the TC offers a high potential for energy saving in the lighting system and by implementing the facade shading mesh even higher energy efficiency levels could be reached.
\end{abstract}

Keywords: Façade shading elements; RTQ-C; energy efficiency; lighting systems; sustainability

\section{RESUMEN}

La búsqueda de una mayor eficiencia energética en el uso de la electricidad ha traído numerosas iniciativas loables, en Brasil bajo la mayor responsabilidad de Procel, con campañas de sensibilización de usuarios, para el etiquetado de electrodomésticos hasta el panorama actual de certificación de edificios. El objetivo principal de este estudio es evaluar el nivel de eficiencia energética a través de los Requisitos Técnicos para la Calidad del Nivel de Eficiencia Energética para Edificios Comerciales, de Servicios y Públicos (RTQ-C / Procel) del Tribunal de Cuentas (TC), parte de patrimonio histórico del Estado de Paraná, ubicado en el Centro Cívico de Curitiba. EI TC consta de dos edificios construidos y un tercer edificio en proyecto: el edificio de la sede, el edificio anexo y la ampliación del edificio anexo. En el Edificio de la Sede se analizaron indicadores de posibles ahorros energéticos derivados de la mejora de los sistemas de iluminación (natural y artificial). En la ampliación del Edificio Anexo se evaluó la aplicabilidad del sistema de sombreado de fachada denominado pantalla tensada. Se comprobó que los edificios existentes tienen un gran potencial de ahorro energético en sistemas de iluminación y que, mejorando los dispositivos de sombreado de fachadas en el proyecto de ampliación del Edificio Anexo, se pueden conseguir mayores niveles de eficiencia energética en el aspecto envolvente.

Palabras clave: Sistemas de sombreado de fachadas; RTQ-C; eficiencia energetica; sistemas de iluminación; sustentabilidad 


\section{Introdução}

Cada vez mais consolida-se a necessidade de uma abordagem conceitual que priorize práticas sustentáveis em suas diferentes formas, sendo uma delas o consumo eficiente de energia. Geller (2003) considera que tanto as fontes quanto as tendências atuais do uso de energia não são sustentáveis, destacando que o uso mundial de energia aumentou dez vezes desde 1900, sendo a maior parte desta energia proveniente de fontes não renováveis.

No Brasil, esse grande crescimento no consumo de energia também é fato. Geller (2003) afirma que o uso total de energia no Brasil cresceu cerca de $250 \%$ no período de 1975 a 2000, aumento provocado, principalmente, pela rápida industrialização e pelos crescentes serviços energéticos: residencial e comercial.

Em razão disto, em 2001, é criada no Brasil a lei da eficiência energética sob o n 10295. No setor público, vários são os decretos elaborados para estipular metas de redução de consumo, de acordo com o Código Legislativo da Eletrobrás (SILVA et al., 2008). Um exemplo destes dispositivos legais seria o Decreto $\mathrm{n}^{\circ}$. 3.330 , de 06 de janeiro de 2000, que estabelece que os edifícios públicos deveriam reduzir em $20 \%$ o consumo de energia elétrica até dezembro de 2002. Não tendo sido cumpridas as metas estipuladas, outro Decreto foi criado, $n^{\circ} .4 .131$ de 14 de fevereiro de 2002, que determinou a redução de consumo de energia elétrica nos edifícios públicos num percentual de 17,5\% a partir de fevereiro de 2002, tendo como referência o consumo no mesmo mês, ocorrido no ano 2000. De acordo com o Balanço Energético Nacional - BEN (BRASIL, 2012), o setor público continua aumentando sua participação no consumo geral de energia elétrica ano a ano. De acordo com o IPEADATA - Instituto de Pesquisa Econômica Aplicada (2013), no Brasil o consumo de energia elétrica no setor comercial aumentou 26 vezes, de $3.051 \mathrm{GWh}$ em 1963 para 79.285 GWh em 2012.

Este artigo tem por objetivo apresentar o nível de eficiência energética geral do Edifício Sede do Tribunal de Contas do Paraná e seus possíveis potenciais de economia assim como o nível de eficiência da envoltória da ampliação do Edifício Anexo, utilizando os Requisitos Técnicos da Qualidade do Nível de Eficiência Energética para Edifícios Comerciais, de Serviços e Públicos (RTQ-C).

\section{Procel E RTQ-C}

O Procel, Programa Nacional de Conservação de Energia Elétrica, foi criado em Dezembro de 1985 pelos Ministérios de Minas e Energia e da Indústria e Comércio e, em 18 de julho de 1991, foi transformado em programa de governo, tendo sua abrangência e responsabilidades ampliadas. $O$ objetivo atual do programa é promover a racionalização da produção e do consumo de energia elétrica, para que se eliminem os desperdícios e se reduzam os custos e os investimentos setoriais (BRASIL, 2010).

Em 1993, foi criado o Selo Procel, com a finalidade de orientar os consumidores no ato da compra de produtos, indicando os que apresentam os melhores níveis de eficiência energética dentro de cada categoria (BRASIL, 2013b).

Através do Procel e em parceria com o INMETRO, foi criado então o Programa de Etiquetagem de Edifícios no Brasil, responsável pela elaboração do documento RTQ-C (Requisitos Técnicos da Qualidade para o Nível de Eficiência Energética de Edifícios Comerciais, Públicos e de Serviços), que especifica requisitos bem como métodos para classificação de edifícios comerciais, de serviços e públicos (Brasil, 2013a). O plano de etiquetagem tem seus fundamentos na Lei n. 10.295 de 17/10/2001, que estabelece a Política Nacional de Conservação e Uso Racional de Energia, e o Decreto n. 4.059, de 19 de dezembro de 2001, que a regulamenta (BRASIL, 2012). 
O Regulamento Técnico da Qualidade do Nível de Eficiência Energética para Edifícios Comerciais, de Serviços e Públicos - RTQ-C - teve seu conteúdo revisado e posteriormente aprovado pela Portaria $\mathrm{n}$. 197, de 28 de maio de 2010, do INMETRO e passou a ser denominado Requisitos Técnicos da Qualidade do Nível de Eficiência Energética para Edifícios Comerciais, de Serviços e Públicos. Em 2012, passou por nova revisão e atualização, publicada na Portaria n. 17 de 16 de janeiro de 2012 (BRASIL, 2012). Em 2013, sofreu novas alterações publicadas na Portaria n. 299 de 19 de junho de 2013 (BRASIL, 2013a).

Segundo o Procel, a economia nos edifícios pode alcançar 30\% para edificações já existentes se estas passarem por uma intervenção do tipo retrofit (reforma e/ou atualização) e até $50 \%$ em edificações novas se forem utilizadas tecnologias energeticamente eficientes desde a concepção inicial do projeto (BRASIL, 2012).

A etiqueta é concedida em dois momentos: na fase de projeto e após a construção do edifício. São avaliados três sistemas, cada qual com seu peso: envoltória, com peso de $30 \%$; sistema de iluminação, com peso de $30 \%$; e condicionamento de ar, com peso de $40 \%$, de forma integral ou parcial. Todos os sistemas individuais têm níveis de eficiência que variam de $A$ (mais eficiente) a $E$ (menos eficiente), com equivalentes numéricos variando entre 5 (mais eficiente) e 1 (menos eficiente). $O$ número de pontos obtidos na Equação Geral irá definir a classificação geral do edifício.

Um dos objetivos do RTQ-C é adequar as construções às condições locais e, para tanto, o regulamento apresenta suas recomendações para cada Zona Bioclimática do país.

\subsection{Pré-Requisitos e Bonificações}

Além da avaliação dos sistemas, para o edifício ser elegível à etiquetagem, é necessário cumprir alguns pré-requisitos, sendo estes divididos em pré-requisitos gerais e específicos (BRASIL, 2013a).

Iniciativas que aumentem a eficiência energética da edificação poderão receber bonificações que variam entre 0 e 1 . Sendo 0 , quando não existe nenhum sistema complementar para o aumento da eficiência, e 1 , quando uma das bonificações foi implementada em sua totalidade ou mais de uma bonificação for atendida parcialmente de forma complementar a alcançar 1 ponto (BRASIL, 2013a).

\subsection{Envoltória}

A avaliação do Sistema de Envoltória faz-se através da determinação de um conjunto de índices referentes às características físicas do edifício. Esses parâmetros compõem a "pele" do edifício (cobertura, fachada e aberturas) e são complementados pelo volume, pela área de piso e pela orientação das fachadas.

Os pré-requisitos iniciais para a envoltória no RTQ-C são: transmitância térmica da cobertura e paredes externas, cores e absortância de superfícies (somente para ZB 02 a 08) e itens relacionados a iluminação zenital. Os itens ficam mais rigorosos na medida em que o nível de eficiência aumenta (BRASIL, 2013a).

\subsection{Sistema de Iluminação}

Os pré-requisitos técnicos de controle do sistema de iluminação variam de acordo com o nível de eficiência pretendido. São eles: divisão de circuitos (exigido nos níveis $A, B$ e C), contribuição da luz natural (exigido nos níveis $A, B$ ) e desligamento automático do sistema de iluminação (exigido no nível $A$ ).

O procedimento para a determinação do nível de eficiência estabelece o limite de densidade de potência instalada de iluminação artificial interna, que varia de A (mais eficiente) até $E$ (menos eficiente). Quanto menor a potência utilizada nas lâmpadas, menor é a energia consumida e mais eficiente torna-se o sistema. A avaliação do sistema pode ser realizada através dos métodos da área ou das atividades. 
No método da área do edifício, este é analisado como um todo. Os limites já consideram a existência de ambientes secundários. Os valores limites máximos de densidade de potência de iluminação, para Instalações Governamentais, variam entre 9,9 e 14,4 (BRASIL, 2012). Além da densidade de potência de iluminação (DPI), é preciso também observar o nível de iluminância dos ambientes para a realização das tarefas, pois a quantidade e qualidade de iluminação em um ambiente também vão depender do tipo de atividade desenvolvida no local.

\subsection{Sistema de Condicionamento de ar}

Os sistemas de condicionamento de ar possuem pré-requisito apenas para o nível de eficiência A. Este pré-requisito diz respeito à espessura mínima de isolamento de tubulações para o sistema de refrigeração e aquecimento, se existente.

Para a classificação do nível de eficiência, os edifícios condicionados artificialmente precisam ter sistemas com eficiência conhecida, sendo por condicionadores de ar do tipo janela ou split com eficiência avaliada pelo INMETRO, ou por condicionadores de ar não etiquetados pelo INMETRO. No primeiro caso, são classificados por meio do nível de eficiência que o INMETRO atribui a cada modelo. No outro caso, são avaliados pelo seu desempenho através de tabelas fornecidas pelo RTQ-C (BRASIL, 2013b).

\section{Descrição do conjunto de edifícios do Tribunal de Contas do Paraná}

O Tribunal de Contas do Estado do Paraná, (Figuras 1 e 2) com projeto de Roberto Gandolfi e José Sanchotene; é composto por dois edifícios. O primeiro deles, o Edifício Sede, foi construído no ano de 1967. O edifício foi executado em concreto armado e em pele de vidro. Na parte externa, o prédio é circundado por um espelho d'água e por brises em concreto armado que apoiam perifericamente a estrutura de cobertura.

O Edifício Sede, com uma área total construída de aproximadamente $5.630 \mathrm{~m}^{2}$, é composto de garagem, subsolo semienterrado, térreo e andar superior. Possui planta livre e blocos de sanitários, elevadores e centrais de ar condicionado. Os ambientes são separados por meio de divisórias. Na pesquisa, foram analisados todos os ambientes de uso laboral do edifício, exceto os blocos de sanitários, elevadores e centrais de ar condicionado.

Já o chamado Edifício Anexo, construído no ano de 1983 para suprir a necessidade de ampliação do Tribunal, também é composto de estrutura em concreto armado e em pele de vidro, possui 06 andares e área total construída de aproximadamente $5.700 \mathrm{~m}^{2}$, a qual não foi considerada no escopo do presente artigo. 
Figura 1: Implantação. Legenda: 1 - Edifício Sede, 2 - Edifício Anexo, 3 - Ligação, 4 - Ampliação do Edifício Anexo.

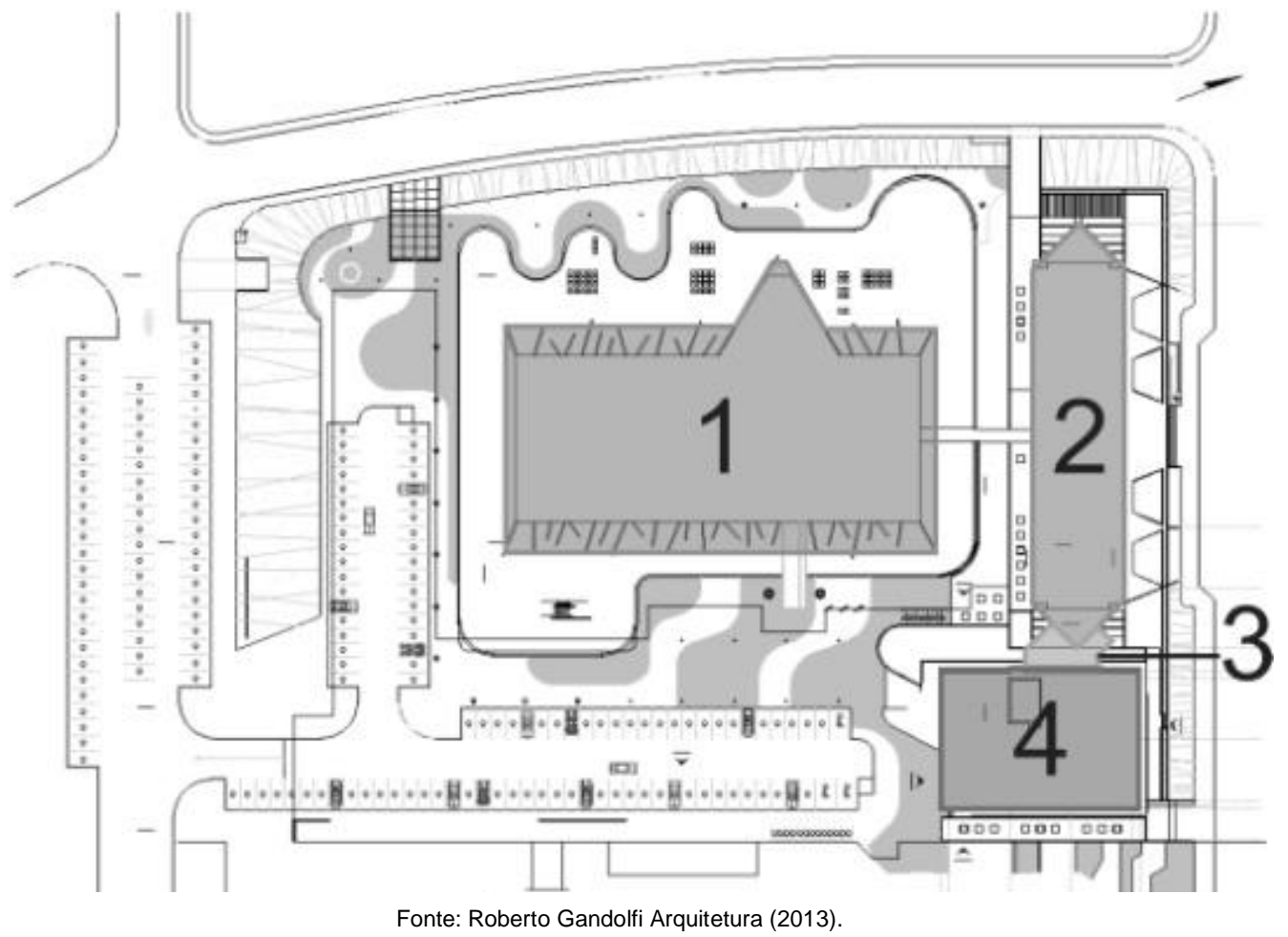

Figura 2: Localização da Ampliação do Edifício Anexo.

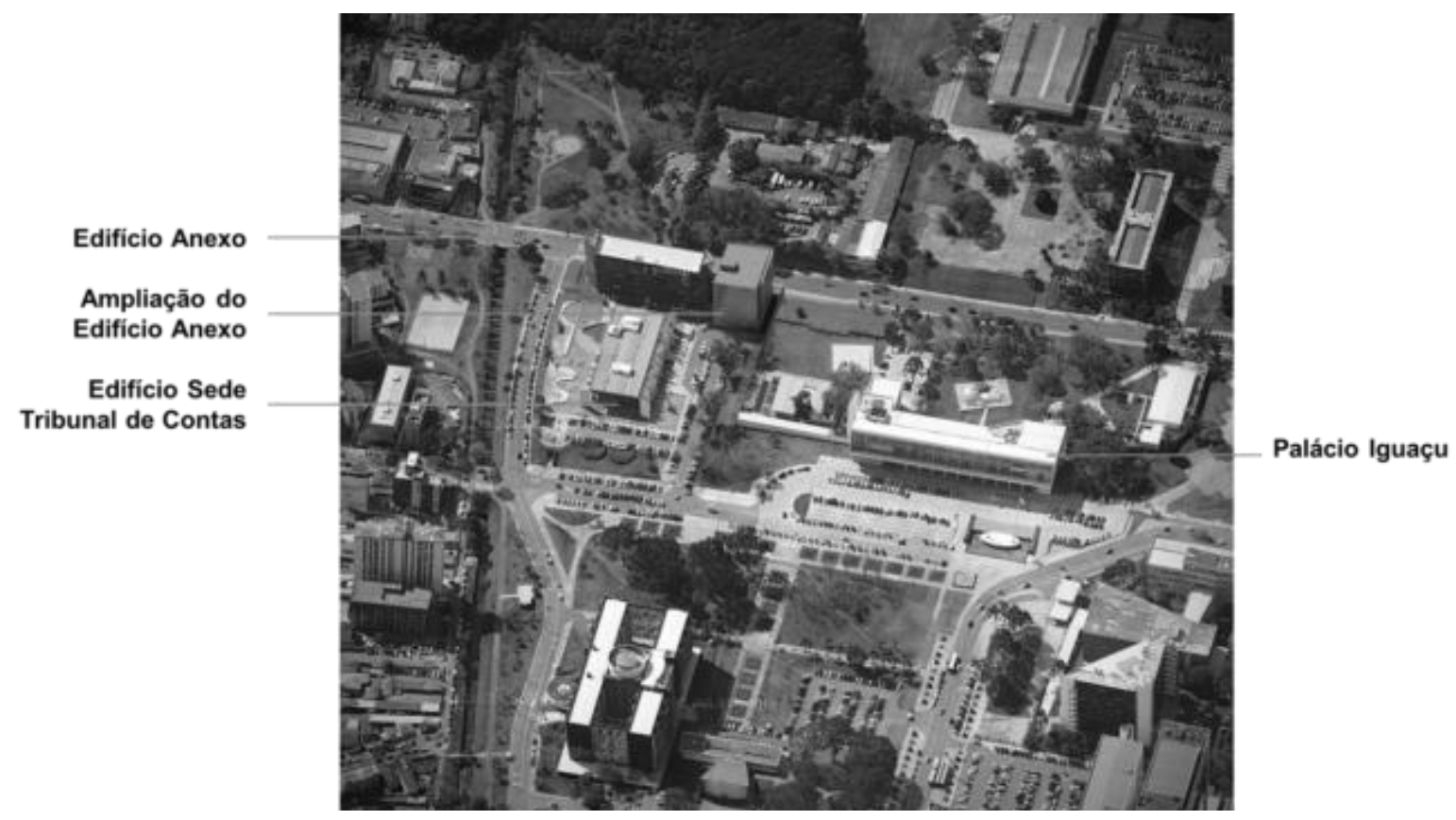

Fonte: Roberto Gandolfi Arquitetura (2013). Imagem Base: Google Maps.

Em 25 de maio de 2012, a Secretaria do Estado da Cultura do Estado do Paraná (Seec), decretou através do Tombo 169 II, o tombamento do Centro Cívico, incluindo diversas construções ali inseridas, dentre elas o Tribunal de Contas. 
Ainda no ano de 2012 foi projetada pelos mesmos arquitetos uma ampliação do Edifício Anexo, contando com 8 andares e um subsolo com garagem e auditório, totalizando 12.140,76 $\mathrm{m}^{2}$ de área construída. Como características formais, o prédio compreende um volume retangular. Também foi projetada uma passagem ligando os dois edifícios a qual não foi considerada no escopo do presente artigo.

\subsection{Levantamento Arquitetônico}

Para a realização da avaliação do nível de eficiência energética do Edifício Sede, o Tribunal de Contas disponibilizou dados arquitetônicos tais como implantação, cortes e elevações, assim como dados de alguns materiais utilizados no edifício, fundamentais para a verificação do item Envoltória do RTQ-C1.

Pelas plantas fornecidas, no projeto original, a cobertura do Edifício Sede deveria ser um telhado verde, mas devido a diversas infiltrações, foi necessária a realização de projeto alternativo para a retirada das plantas e colocação de telhas, sendo mantida somente a pequena parte da cobertura original, composta de telha translúcida.

Para a análise da envoltória, foram levantados os seguintes dados, além do levantamento do projeto arquitetônico: área de projeção da cobertura (m2); área total construída (m2); área de fachadas e cobertura (m2); volume total dos edifícios (m3); área total de piso (m2); ângulos de sombreamento (o); área de aberturas envidraçadas (m2); percentual de abertura das fachadas (\%); fator solar das aberturas e materiais da cobertura (\%).

No levantamento arquitetônico interno realizado por inspeção, todos os ambientes inspecionados foram fotografados em 360o e foram coletadas informações quanto a características físicas e do sistema de iluminação tais como: área útil $(\mathrm{m} 2)$, pé-direito $(\mathrm{m})$, número de funcionários por ambiente, período e horários de uso do ambiente, quantidade de interruptores, quantidade de luminárias, quantidade e tipologia de lâmpadas acesas e apagadas ou queimadas.

No subsolo parcialmente enterrado, foram vistoriados 14 ambientes, com uma área total de 639,55 m2. No térreo, foram vistoriados 18 ambientes, com uma área total de $715,15 \mathrm{~m} 2$. E, no andar superior, todos os 21 ambientes foram inspecionados, totalizando a área de 686,01 m2. Todos os pavimentos possuem forro modulado para luminárias de embutir com lâmpadas fluorescentes de 40 e $32 \mathrm{~W}$, variando de ambiente para ambiente.

Para a realização das análises da ampliação do Edifício Anexo, como esta ainda não estava concluída, foram utilizados os dados da última versão do projeto executivo. Com relação aos materiais da envoltória desse edifício, praticamente todas as faces são fechadas com panos de vidro e duas faces (faces 1 e 2 conforme a Figura 3) utilizam de um artifício de sombreamento chamado de tela tensionada. Como o material e a tecnologia são recentes e ainda pouco explorados no Brasil, estes foram alguns dos motivos para a realização do presente estudo e da intenção da análise da envoltória do Edifício Anexo com uso do RTQ-C.

\footnotetext{
${ }^{1}$ Por questões de segurança, o Tribunal de Contas do Paraná pediu que não fossem publicadas as plantas com suas divisões internas e posicionamento de salas neste estudo.
} 
Figura 3: Sobreposição do edifício em rosa dos ventos para definição da orientação de cada fachada.

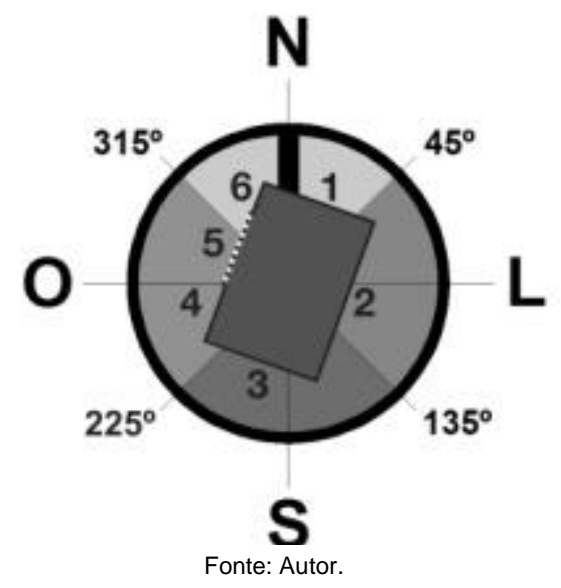

\section{Aplicação do RTQ-C no edifício sede}

A análise do Edifício Sede foi realizada quanto aos três sistemas: envoltória, iluminação e condicionamento de ar, todos através do método prescritivo indicado pelo RTQ-C. E, posteriormente, foi avaliado o edifício por completo para a obtenção de sua classificação geral.

\subsection{Análise dos Pré-requisitos Gerais}

Quanto à análise dos pré-requisitos gerais, mesmo que o pré-requisito geral de divisão de circuitos seja exigido pelo RTQ-C somente para os edifícios construídos posteriormente a junho de 2009, foi observado no edifício estudado que os circuitos elétricos são separados por uso final. No caso do pré-requisito geral de aquecimento de água, a edificação usa o mínimo de aquecimento por ser um prédio público.

\subsection{Aplicação do RTQ-C - Análise da Envoltória}

Como descrito anteriormente, alguns índices e pré-requisitos devem ser atendidos para cada nível de eficiência.

\subsubsection{Pré-Requisitos}

Para o cálculo do primeiro pré-requisito, transmitância térmica $(U)$, foram levantados os dados referentes aos materiais das paredes externas e da cobertura, necessários para o cálculo. Quanto à cobertura, o edifício possui camadas compostas de telha metálica com espessura de $0,4 \mathrm{~cm}$, câmara de ar com espessura de $20 \mathrm{~cm}$ e laje maciça de $10 \mathrm{~cm}$ de espessura, conforme corte apresentado (Figura 4).

Figura 4: Corte com as camadas da cobertura do Edifício Sede.

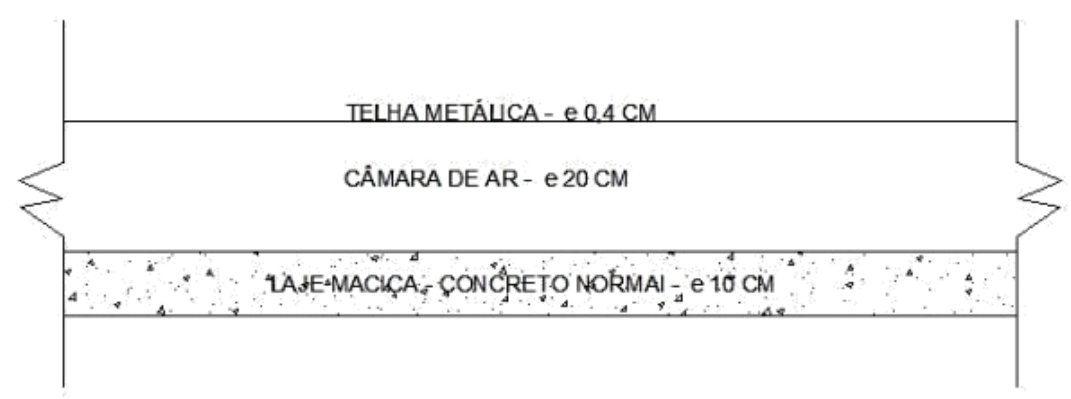

Fonte: Autor 
Utilizando-se dos valores para a determinação deste pré-requisito, obtidos através das tabelas A.1, B.1 da NBR 15220 - parte 02 (ABNT, 1992), calculou-se o valor da transmitância térmica da cobertura (Ucob), sendo este o inverso da resistência térmica total, $\mathrm{Ucob}=2,09 \mathrm{~W} /(\mathrm{m} 2$. $\mathrm{K})$, atingindo classificação $E$, sendo que transmitância máxima permitida para o nível D seria 2,00 W/ (m2. K). Quanto às paredes externas, o edifício possui fachada envidraçada, com vidro comum $06 \mathrm{~mm}$, na cor bronze, não sendo esta considerada no cálculo de transmitância térmica. Segundo o RTQ-C, a transmitância térmica de paredes externas só é calculada para componentes opacos, sendo assim as paredes externas do edifício sede não entram no cálculo.

O segundo pré-requisito, cores e absortância de superfícies, não é obrigatório para a Zona Bioclimática 1. O limite estipulado é desconsiderado para permitir absortâncias elevadas que podem aumentar os ganhos térmicos por radiação nos edifícios no inverno.

O terceiro pré-requisito, iluminação zenital, foi analisado, pois no Edifício Sede há uma pequena faixa de $50 \mathrm{~m} 2$ de cobertura de policarbonato na área do plenário. Sendo a área total de cobertura $1.340 \mathrm{~m} 2$, o Percentual de abertura zenital na cobertura (PAZ) é de 3,73\% e o Fator Solar (FS) da telha ondulada em policarbonato é 0,85, segundo Lamberts et al. (1997).

Pode-se concluir que, como o valor do FS recomendado para o percentual de abertura zenital acima citado é de 0,52 , este terceiro pré-requisito da envoltória do edifício não atende os critérios exigidos para alcançar os níveis $A$ e $B$.

\subsubsection{Cálculo do Índice de Consumo da Envoltória (ICenv) e Classificação pelo RTQ-C}

Para determinar o nível de eficiência da envoltória, é necessário calcular um indicador de consumo obtido através da equação descrita anteriormente. Para tanto, foram calculadas diversas variáveis e, posteriormente, essas variáveis foram aplicadas na equação geral.

Com o resultado que foi obtido, pode-se concluir que, para o Edifício Sede, a classificação do nível de eficiência energética da envoltória seria $D$, mas como alguns dos pré-requisitos exigidos para este nível não foram atendidos (Ucobe Upar), a classificação geral da envoltória cai para E com EqNumEnv igual a 1.

\subsection{Aplicação do RTQ-C - Análise do Sistema de Iluminação Artificial}

Para a análise do sistema de iluminação artificial, foram levantados diversos dados no edifício. Foi observado que nos 53 ambientes avaliados não havia uma padronização na potência das lâmpadas utilizadas, tanto do modelo quanto do fabricante. Foram encontradas num mesmo ambiente lâmpadas de 40 e $32 \mathrm{~W}$, em outros lâmpadas de 40 e 20W, ou ainda em outro lâmpadas de 40, 32 e 20W. Em alguns ambientes foram encontradas também lâmpadas que já não estavam mais funcionando ou mesmo luminárias sem lâmpadas, prejudicando a iluminância do local.

\subsubsection{Pré-requisitos}

Para a avaliação do primeiro pré-requisito, divisão de circuitos, foi observado por meio do levantamento arquitetônico interno que nem todos os ambientes possuem dispositivo de controle para acionamento independente da iluminação interna. Alguns ambientes são alimentados diretamente do quadro de disjuntores e outros possuem dispositivo de acionamento em ambiente próximo. $\mathrm{Na}$ Tabela 4, pode-se observar que o número médio de interruptores por ambiente está abaixo do recomendado pelo RTQ-C, sendo que é necessário que cada ambiente tenha pelo menos um acendimento independente. Por este 
motivo, como orienta o RTQ-C, foi realizado o cálculo de ponderação2 para cada ambiente do Edifício Sede, onde existem salas sem dispositivo de acionamento para iluminação e ambientes onde estes dispositivos estão presentes. Como resultado deste pré-requisito, o Edifício Sede alcançou nível D.

Para o segundo pré-requisito, contribuição de luz natural, não foi observada a diferenciação de acendimento para luminárias das fileiras mais próximas às aberturas externas no edifício.

Quanto ao terceiro pré-requisito, desligamento automático do sistema de iluminação, não foi observado nenhum dispositivo desse tipo no edifício.

\subsubsection{Determinação do nível de eficiência}

A determinação do nível de eficiência pelo limite de potência de iluminação artificial interna foi averiguada através do método da área do edifício.

No Edifício Sede, todos os andares e seus referidos ambientes foram inspecionados e analisados, obtendo-se o valor da eficiência do sistema de iluminação integral.

$\mathrm{Na}$ Tabela 1, podem ser observados alguns dos dados levantados nas inspeções. Pode-se verificar que, em média, $90 \%$ das luminárias nos ambientes estavam em funcionamento, e que, mesmo sem a utilização da capacidade total de lâmpadas ligadas, o nível de eficiência segundo o RTQ-C ficou classificado como "E" em todos os andares inspecionados.

Tabela 1: Descritivo/Resumo dos resultados inspecionados

\begin{tabular}{l|c|c|c|c}
\multicolumn{1}{c|}{ Discriminativo } & \multicolumn{4}{c}{ Ed. Sede } \\
\cline { 2 - 5 } & subsolo & térreo & superior & total \\
\hline 1. Número de ambientes & 14 & 18 & 21 & 53 \\
\hline 2. Área total & 651,71 & 691,59 & 686,81 & 2030,11 \\
\hline 3. Número de luminárias & 181 & 212 & 203 & 596 \\
\hline 4. Número médio de luminárias/ambiente & 13 & 12 & 10 & 11 \\
\hline 5. Capacidade total de lâmpadas & 362 & 424 & 406 & 1192 \\
\hline 6. Número de lâmpadas em funcionamento & 312 & 454 & 380 & 1146 \\
\hline 7. Fator manutenção lâmpadas & 0,8 & 0,8 & 0.8 & 0,8 \\
\hline 8. Potência total das lâmpadas & 14480 & 16960 & 16240 & 47680 \\
\hline 9. Potência total de lâmpadas em funcionamento & 12056 & 20450 & 13560 & 46066 \\
\hline 10. Número de interruptores & 20 & 14 & 14 & 48 \\
\hline 11. Número médio de interruptores/ambiente & 1,4 & 0,8 & 0,7 & 0,9 \\
\hline 12. Potência/m² em funcionamento & 18,50 & 29,57 & 19,74 & 22,60 \\
\hline 13. Nível de eficiência pelo RTQ-C & $\mathrm{E}$ & $\mathrm{E}$ & $\mathrm{E}$ & $\mathrm{E}$ \\
\hline 14. Potência/m² capacidade total de lâmpadas & 22,22 & 24,52 & 23,65 & 23,49 \\
\hline 15. Nível de eficiência pelo RTQ-C & $\mathrm{E}$ & $\mathrm{E}$ & $\mathrm{E}$ & $\mathrm{E}$ \\
\hline${ }^{*}$ Relação entre os itens 6 e 5. & & & &
\end{tabular}

Fonte: Autor

${ }^{2} \mathrm{O}$ cálculo de ponderação é feito entre os níveis de eficiência e potência instalada dos ambientes que não atenderam aos pré-requisitos e a potência instalada e o nível de eficiência encontrado para o sistema de iluminação (BRASIL, 2012). 
Isto traz como resultado um EqNumDPI igual a 1, a ser utilizado posteriormente no cálculo da eficiência geral do edifício.

\subsection{Aplicação do RTQ-C - Análise do Sistema de Ar Condicionado}

O Tribunal de Contas do Paraná possui sistema central de ar condicionado nos dois edifícios existentes. $O$ Edifício Sede é composto por sistema central com equipamento de condensação a ar, com condensador sendo 2 unidades Chiller marca Trane, modelo RTAA090, com capacidades individual e total de 322,16 kW e 644 kW respectivamente e COP de 2,93.

\subsubsection{Pré-Requisitos}

Os pré-requisitos do sistema de condicionamento de ar são exigidos somente para o nível A. Como o Edifício Sede não atingiu a classificação do nível $A$ na avaliação dos equipamentos, fica tal avaliação dispensada dos pré-requisitos.

\subsubsection{Determinação do nível de eficiência}

No caso dos sistemas centrais de condicionamento de ar, considerados pelo RTQ-C como sistemas de ar não regulamentados pelo INMETRO, o nível de eficiência é obtido através de tabelas fornecidas pelo RTQ-C, como mencionado anteriormente.

Tabela 2: Análise dos dados do sistema de ar condicionado - Edifício Sede

\begin{tabular}{|c|c|c|}
\hline Item & Descrição & Edifício Sede \\
\hline \multirow{7}{*}{ 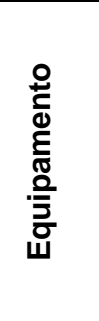 } & Tipo de equipamento & Condensação a ar, com compressor \\
\hline & Fabricante & Trane \\
\hline & Modelo & RTAA090 \\
\hline & Quantidade de equipamentos & 2 \\
\hline & Capacidade Total (TR) & 183,2 \\
\hline & Capacidade de refrigeração Total (kW) & 644,31 \\
\hline & COP & 2,93 \\
\hline \multirow{4}{*}{ 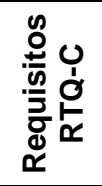 } & Capacidade - faixa (kW) & $\geq 528 \mathrm{~kW}$ \\
\hline & Nível A e B (Tab. 5.5) - COP & 3,73 \\
\hline & Nível C (Tab. 5.8) - COP mínimo & 2,80 \\
\hline & Nível D (Tab. 5.10) - COP mínimo & 2,50 \\
\hline \multirow{4}{*}{ 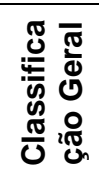 } & Classificação do equipamento & $\mathrm{C}$ \\
\hline & Equivalente Numérico & 3 \\
\hline & EqNumCA edifício & $\mathrm{C}$ \\
\hline & Classificação do edifício & 3 \\
\hline
\end{tabular}

Sendo assim, os dados técnicos dos equipamentos fornecidos pelo fabricante foram comparados aos dados constantes nas tabelas do RTQ-C em função do tipo de sistema de condicionamento de ar (Tabela 2).

Como resultado, foi constatado que o sistema de condicionamento de ar do Edifício Sede obteve classificação C.

\subsection{Aplicação do RTQ-C - Análise do nível de eficiência geral do Edifício Sede}

Depois de obtidos os equivalentes numéricos da envoltória, da iluminação e do condicionamento de ar e não havendo bonificações, os dados foram aplicados na fórmula para o cálculo geral da eficiência do 
Edifício Sede. Sendo os valores das variáveis encontradas EqNumEnv: 1, EqNumV:0, EqNumDPI: 1, EqNumCA: 3, AC: 2.198 m2, AU: 2.198 m2, APT: 0, ANC: 0, b: 0.

O valor final obtido é 0,75 . O que leva o edifício à classificação de eficiência energética geral equivalente a "E".

\subsection{Propostas de melhoria do nível do RTQ-C no sistema de iluminação do Edifício Sede}

Assumindo-se que, em um prédio tombado, melhorias na envoltória seriam vetadas e que mudanças no sistema de climatização poderiam resultar em custos elevados, foram realizados estudos individuais de cada ambiente existente no Edifício Sede, através do software Lumisoft, para averiguar a possível melhora no nível de eficiência do RTQ-C especificamente no que diz respeito à iluminação artificial. Foram realizados 4 estudos em cada ambiente (E1 a $\mathrm{E} 4)$, sendo os dois primeiros com as luminárias atuais e os outros dois trocando-se o modelo da luminária e da lâmpada para um conjunto mais eficiente.

Variou-se também nos dois casos a quantidade de luminárias, primeiramente aplicando-se a quantidade encontrada in loco (E1 e E3) e posteriormente em número reduzido ((E2 e E4). Foi adotado como critério o limite recomendado de 500 lux pela NBR ISO/CIE 8995-1 (ABNT, 2013) para as atividades exercidas no ambiente.

\subsubsection{Análise do pavimento subsolo}

Por meio de simulação realizada com o software Lumisoft, considerando-se a implantação de luminárias e lâmpadas mais eficientes FAC06-E228, o nível de eficiência do sistema de iluminação artificial poderia ser aumentado para "A", desconsiderando os pré-requisitos. Observa-se também que, quanto menor a área do ambiente, mais difícil o atingimento do nível de eficiência máxima desejado, mesmo utilizando-se luminárias eficientes, assim como descrito na norma ASHRAE/IES 90.1-1989 (ASHRAE/IES, 1989).

Considerando-se a simulação dos ambientes com as luminárias existentes, observou-se que alguns dos ambientes não atingiam a iluminância média mínima de 500 lux exigida pela NBR ISO/CIE 8995-1 (ABNT, 2013). Nesses casos, não foram atribuídos níveis de eficiência aos ambientes. A Tabela 3 apresenta resultados obtidos no subsolo para areas distintas; em ambientes menores (Sala 04), mesmo com melhorias, obtém-se uma variação do nível de eficiência mais discreta que em ambientes maiores (Tabela 4). 
Tabela 3: Níveis de iluminância nas salas com áreas variadas - Subsolo

\begin{tabular}{|c|c|c|c|c|c|c|c|c|c|}
\hline & $\begin{array}{l}\text { Quantidade } \\
\text { luminárias } \\
\text { existentes }\end{array}$ & $\begin{array}{c}\text { Modelo } \\
\text { Luminária } \\
\text { (simulação) }\end{array}$ & $\mathbf{m}^{2}$ & $\begin{array}{l}\text { Quantidade } \\
\text { luminárias } \\
\text { propostas }\end{array}$ & $\begin{array}{l}\text { Iluminância } \\
\text { Média } \\
\text { (Lux) }\end{array}$ & $\begin{array}{c}\text { Potência } \\
\text { / } \\
\text { luminária } \\
\text { (W) }\end{array}$ & $\begin{array}{l}\text { Potência } \\
\text { total } \\
\text { (W) }\end{array}$ & $\begin{array}{l}\text { Potência } \\
\text { (W) } / \mathrm{m}^{2}\end{array}$ & $\begin{array}{c}\text { Nível } \\
\text { RTQ-C }\end{array}$ \\
\hline \multirow{2}{*}{ 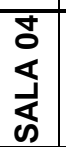 } & \multirow{2}{*}{2} & E2 - CAN01-E232 & 8,4 & 3 & 669,2 & 64 & 192 & 22,86 & $E$ \\
\hline & & E3 - FAC06-E228 & 8,4 & 2 & 510,6 & 56 & 112 & 13,33 & C \\
\hline \multirow{4}{*}{$\begin{array}{l}5 \\
\frac{5}{4} \\
\text { ๘ }\end{array}$} & \multirow{4}{*}{10} & E1 - CAN01-E232 & 36 & 10 & 792,2 & 64 & 640 & 17,78 & $E$ \\
\hline & & E2 - CAN01-E232 & 36 & 7 & 596,5 & 64 & 448 & 12,44 & $\mathrm{C}$ \\
\hline & & E3 - FAC06-E228 & 36 & 10 & 876,2 & 56 & 560 & 15,56 & $E$ \\
\hline & & E4 - FAC06-E228 & 36 & 6 & 541,3 & 56 & 336 & 9,33 & $A$ \\
\hline \multirow{4}{*}{ 造 } & \multirow{4}{*}{21} & E1 - CAN01-E232 & 67,1 & 21 & 1042,5 & 64 & 1344 & 20,03 & $E$ \\
\hline & & E2 - CAN01-E232 & 67,1 & 11 & 547,2 & 64 & 704 & 10,49 & $\mathrm{~B}$ \\
\hline & & E3 - FAC06-E228 & 67,1 & 21 & 1144,2 & 56 & 1176 & 17,53 & $\mathrm{E}$ \\
\hline & & E4 - FAC06-E228 & 67,1 & 10 & 522,2 & 56 & 560 & 8,35 & A \\
\hline \multirow{4}{*}{ 邑 } & \multirow{4}{*}{28} & E1 - CAN01-E232 & 97,3 & 28 & 886,2 & 64 & 1792 & 18,42 & $E$ \\
\hline & & E2 - CAN01-E232 & 97,3 & 20 & 510,5 & 64 & 1280 & 13,16 & $\mathrm{D}$ \\
\hline & & E3 - FAC06-E228 & 97,3 & 28 & 886,2 & 56 & 1568 & 16,12 & $E$ \\
\hline & & E4 - FAC06-E228 & 97,3 & 14 & 523,9 & 56 & 784 & 8,06 & $A$ \\
\hline \multirow{4}{*}{ 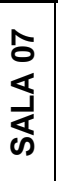 } & \multirow{4}{*}{50} & E1 - CAN01-E232 & 241,95 & 50 & 706,3 & 64 & 3200 & 13,23 & $\mathrm{D}$ \\
\hline & & E2 - CAN01-E232 & 241,95 & 36 & 500,3 & 64 & 2304 & 9,52 & A \\
\hline & & E3 - FAC06-E228 & 241,95 & 50 & 767,2 & 56 & 2800 & 11,57 & $\mathrm{C}$ \\
\hline & & E4 - FAC06-E228 & 241,95 & 34 & 536,2 & 56 & 1904 & 7,87 & $\mathrm{~A}$ \\
\hline
\end{tabular}

Legenda: $\square$ Análise mais eficiente do ambiente.

Tabela 4: Resumo do melhor nível de eficiência atingido geral e nos ambientes do pavimento subsolo

\begin{tabular}{c|c|c}
\hline PAVIMENTO & $\begin{array}{c}\text { NIVEL EFICIÉNCIA } \\
\text { (máximo atingido) }\end{array}$ & $\boldsymbol{m}^{\mathbf{2}}$ \\
\hline SUBSOLO (GERAL) & $\boldsymbol{A}$ & $\mathbf{6 4 0}$ \\
\hline SALA 04 & C & 8 \\
\hline SALA 03 & B & 10 \\
\hline SALA 06 & B & 10 \\
\hline SALA 10 & A & 19 \\
\hline SALA 02 & A & 21 \\
\hline SALA 05 & A & 31 \\
\hline SALA 01 & A & 36 \\
\hline SALA 23 & A & 43 \\
\hline SALA 08 & A & 52 \\
\hline SALA 09 & A & 67 \\
\hline SALA 50 & A & 97 \\
\hline SALA 07 & A & 241 \\
\hline \multicolumn{2}{|c|}{ Fonte: Autor }
\end{tabular}

\subsubsection{Análise do pavimento térreo}

Nota-se que a simples alteração da potência instalada por luminária não traz variação do nível de eficiência, devendo haver também a redução da quantidade de luminárias (Tabela 5). Novamente, o nível de eficiência não se altera significativamente em salas com pequenas dimensões. Entretanto, mesmo 
nesses casos, a simulação mostrou que a densidade de potência pode ser reduzida até $66 \%$ (Sala 25$)$. Os resultados agrupados são mostrados na Tabela 6.

Tabela 5: Níveis de iluminância nas salas com áreas variadas - Térreo

\begin{tabular}{|c|c|c|c|c|c|c|c|c|c|}
\hline & $\begin{array}{l}\text { Quantidade } \\
\text { luminárias } \\
\text { existentes }\end{array}$ & $\begin{array}{l}\text { Modelo } \\
\text { Luminária } \\
\text { (simulação) }\end{array}$ & $\mathrm{m}^{2}$ & $\begin{array}{l}\text { Quantidade } \\
\text { luminárias } \\
\text { Propostas }\end{array}$ & $\begin{array}{l}\text { Iluminância } \\
\text { Média } \\
\text { (Lux) }\end{array}$ & \begin{tabular}{|c|} 
Potência \\
$/$ \\
Iuminária \\
(W) \\
\end{tabular} & $\begin{array}{c}\text { Potência } \\
\text { total } \\
\text { (W) }\end{array}$ & $\begin{array}{l}\text { Potência } \\
\text { (W) / } \mathbf{m}^{2}\end{array}$ & $\begin{array}{l}\text { Nível } \\
\text { RTQ- } \\
\text { C }\end{array}$ \\
\hline \multirow{4}{*}{ 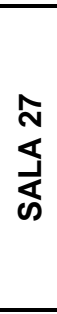 } & \multirow{4}{*}{5} & $\begin{array}{c}\text { E1 - CAN01- } \\
\text { E232 }\end{array}$ & 15 & 5 & 826,4 & 64 & 320 & 21,33 & $\mathrm{E}$ \\
\hline & & $\begin{array}{c}\text { E2 - CAN01- } \\
\text { E232 }\end{array}$ & 15 & 3 & 502,3 & 64 & 192 & 12,80 & C \\
\hline & & $\begin{array}{c}\text { E3 - FAC06- } \\
\text { E228 }\end{array}$ & 15 & 5 & 927,3 & 56 & 280 & 18,67 & $E$ \\
\hline & & $\begin{array}{c}\text { E4 - FAC06- } \\
\text { E228 }\end{array}$ & 15 & 3 & 557,7 & 56 & 168 & 11,20 & B \\
\hline \multirow{4}{*}{$\frac{\stackrel{2}{4}}{\frac{5}{4}}$} & \multirow{4}{*}{13} & $\begin{array}{c}\text { E1 - CAN01- } \\
\text { E232 } \\
\end{array}$ & 25 & 13 & 1400 & 64 & 832 & 33,28 & $\mathrm{E}$ \\
\hline & & $\begin{array}{c}\text { E2 - CAN01- } \\
\text { E232 }\end{array}$ & 25 & 5 & 542,6 & 64 & 320 & 12,80 & C \\
\hline & & $\begin{array}{c}\text { E3 - FAC06- } \\
\text { E228 }\end{array}$ & 25 & 13 & 1583,5 & 56 & 728 & 29,12 & $\mathrm{E}$ \\
\hline & & $\begin{array}{c}\text { E4 - FAC06- } \\
\text { E228 }\end{array}$ & 25 & 5 & 614,2 & 56 & 280 & 11,20 & B \\
\hline \multirow{4}{*}{ : } & \multirow{4}{*}{10} & $\begin{array}{c}\text { E1 - CAN01- } \\
\text { E232 }\end{array}$ & 41,3 & 10 & 683,7 & 64 & 640 & 15,50 & $\mathrm{E}$ \\
\hline & & $\begin{array}{c}\text { E2 - CAN01- } \\
\text { E232 }\end{array}$ & 41,3 & 7 & 515,3 & 64 & 448 & 10,85 & $\mathrm{~B}$ \\
\hline & & $\begin{array}{c}\text { E3 - FAC06- } \\
\text { E228 }\end{array}$ & 41,3 & 10 & 756,7 & 56 & 560 & 13,56 & D \\
\hline & & $\begin{array}{c}\text { E4 - FAC06- } \\
\text { E228 }\end{array}$ & 41,3 & 7 & 573,1 & 56 & 392 & 9,49 & A \\
\hline \multirow{7}{*}{$\frac{n}{\frac{5}{4}}$} & \multirow{7}{*}{18} & $\begin{array}{c}\text { E1 - CAN01- } \\
\text { E232 }\end{array}$ & 55,8 & 18 & 950,5 & 64 & 1152 & 20,65 & $E$ \\
\hline & & $\begin{array}{c}\text { E2 - CAN01- } \\
\text { E232 }\end{array}$ & 55,8 & 10 & 541,4 & 64 & 640 & 11,47 & C \\
\hline & & $\begin{array}{c}\text { E3 - FAC06- } \\
\text { E228 }\end{array}$ & 55,8 & 18 & 1050,2 & 56 & 1008 & 18,06 & $\mathrm{E}$ \\
\hline & & $\begin{array}{c}\text { E4 - FAC06- } \\
\text { E228 } \\
\end{array}$ & 55,8 & 9 & 528,4 & 56 & 504 & 9,03 & A \\
\hline & & $\begin{array}{c}\text { E2 - CAN01- } \\
\text { E232 }\end{array}$ & 89,15 & 15 & 531,8 & 64 & 960 & 10,77 & B \\
\hline & & $\begin{array}{c}\text { E3 - FAC06- } \\
\text { E228 }\end{array}$ & 89,15 & 30 & 1146,4 & 56 & 1680 & 18,84 & $\mathrm{E}$ \\
\hline & & $\begin{array}{c}\text { E4 - FAC06- } \\
\text { E228 }\end{array}$ & 89,15 & 13 & 546,8 & 56 & 728 & 8,17 & A \\
\hline \multirow{4}{*}{$\frac{N}{\frac{5}{4}}$} & \multirow{4}{*}{28} & $\begin{array}{c}\text { E1 - CAN01- } \\
\text { E232 }\end{array}$ & 100,9 & 28 & 878,8 & 64 & 1792 & 17,76 & $\mathrm{E}$ \\
\hline & & $\begin{array}{c}\text { E2 - CAN01- } \\
\text { E232 }\end{array}$ & 100,9 & 16 & 509,5 & 64 & 1024 & 10,15 & B \\
\hline & & $\begin{array}{c}\text { E3 - FAC06- } \\
\text { E228 }\end{array}$ & 100,9 & 28 & 955,3 & 56 & 1568 & 15,54 & $\mathrm{E}$ \\
\hline & & $\begin{array}{c}\text { E4 - FAC06- } \\
\text { E228 }\end{array}$ & 100,9 & 15 & 523 & 56 & 840 & 8,33 & A \\
\hline
\end{tabular}


Tabela 6: Resumo do melhor nível de eficiência atingido geral e nos ambientes do pavimento térreo

\begin{tabular}{c|c|c}
\hline PAVIMENTO & $\begin{array}{c}\text { NIVEL EFICIÉNCIA } \\
\text { (máximo atingido) }\end{array}$ & $\boldsymbol{m}^{\mathbf{2}}$ \\
\hline TÉRREO (GERAL) & $\boldsymbol{A}$ & $\mathbf{8 7 4}$ \\
\hline SALA 27 & $\mathrm{B}$ & 15 \\
\hline SALA 22 & $\mathrm{D}$ & 16 \\
\hline SALA 18 & $\mathrm{A}$ & 17 \\
\hline SALA 21 & $\mathrm{A}$ & 17 \\
\hline SALA 11 & $\mathrm{B}$ & 21 \\
\hline SALA 25 & $\mathrm{B}$ & 25 \\
\hline SALA 14 & $\mathrm{B}$ & 27 \\
\hline SALA 16 & $\mathrm{B}$ & 27 \\
\hline SALA 13 & $\mathrm{A}$ & 30 \\
\hline SALA 29 & $\mathrm{A}$ & 32 \\
\hline SALA 28 & $\mathrm{A}$ & 41 \\
\hline SALA 24 & $\mathrm{A}$ & 42 \\
\hline SALA 17 & $\mathrm{A}$ & 44 \\
\hline SALA 19 & $\mathrm{A}$ & 50 \\
\hline SALA 15 & $\mathrm{A}$ & 55 \\
\hline SALA 20 & A & 59 \\
\hline SALA 26 & A & 89 \\
\hline SALA 12 & A & 100 \\
\hline Fonte: Autor & &
\end{tabular}

\section{6.3 Análise do pavimento superior}

No piso superior, espaço utilizado pelos conselheiros e suas equipes, alguns ambientes são bem pequenos. Como observado nos demais pavimentos, pequenas áreas internas acarretam em potencial mais baixo na eficientização do sistema de iluminação. Por essa razão, o nível de eficiência geral deste pavimento atingiu o nível "B", ao contrário dos demais pavimentos (Tabela 7).

Tabela 7: Resumo do melhor nível de eficiência atingido geral e nos ambientes do pavimento superior

\begin{tabular}{|c|c|c|}
\hline PAVIMENTO & $\begin{array}{l}\text { NIVEL EFICIÉNCIA } \\
\text { (máximo atingido) }\end{array}$ & $m 2$ \\
\hline $\begin{array}{c}\text { SUPERIOR } \\
\text { (GERAL) }\end{array}$ & 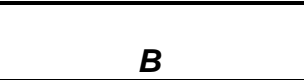 & 685 \\
\hline SALA 39 & $\mathrm{D}$ & 7 \\
\hline SALA 32 & C & 9 \\
\hline SALA 45 & $\mathrm{E}$ & 10 \\
\hline SALA 47 & $E$ & 10 \\
\hline SALA 49 & $E$ & 10 \\
\hline SALA 41 & $\mathrm{C}$ & 18 \\
\hline SALA 31 & B & 27 \\
\hline SALA 46 & $A$ & 28 \\
\hline SALA 48 & $A$ & 29 \\
\hline SALA 40 & A & 30 \\
\hline SALA 36 & $A$ & 38 \\
\hline SALA 35 & $A$ & 38 \\
\hline SALA 30 & $A$ & 39 \\
\hline SALA 44 & A & 39 \\
\hline SALA 33 & $A$ & 41 \\
\hline SALA 34 & $A$ & 42 \\
\hline SALA 37 & $A$ & 42 \\
\hline SALA 43 & $A$ & 49 \\
\hline SALA 38 & A & 51 \\
\hline SALA 51 & $A$ & 54 \\
\hline SALA 42 & $A$ & 70 \\
\hline
\end{tabular}


Os estudos realizados no Edifício Sede com o auxílio do software Lumisoft, mostram que o nível de eficiência do RTQ-C poderia ser elevado ao nível A, caso fosse efetuada a mudança para o conjunto de luminárias/lâmpadas eficientes, em número reduzido (Tabela 8), desconsiderando-se os pré-requisitos. Salienta-se que o novo layout de distribuição dessas luminárias deveria ser estudado em maior profundidade.

\begin{tabular}{|c|c|c|c|c|c|}
\hline Tabela 8: & & & & & \\
\hline níveis & Piso & RTQ-C & $\mathrm{W} / \mathrm{m}^{2}$ Existente & RTQ-C* & $\mathrm{W} / \mathrm{m}^{2}$ Eficiente \\
\hline iluminação: & Subsolo & $\mathrm{E}$ & 21,9 & $\mathrm{~A}$ & 9,29 \\
\hline versus eficiente & Térreo & E & 25,03 & A & 9,70 \\
\hline versus enciente & Superior & $\mathrm{E}$ & 20,82 & $B$ & 10,55 \\
\hline & Geral & $E$ & 22,81 & $\boldsymbol{A}$ & 9,85 \\
\hline
\end{tabular}

*Valor RTQ-C aplicando-se conjunto de luminárias eficiente

Fonte: Autor

\section{Aplicação do RTQ-C na ampliação do edifício anexo - análise de melhoramentos da envoltória}

Para a realização do estudo e análise da eficiência energética da envoltória da ampliação do Edifício Anexo foram coletados dados necessários para o enquadramento de sua eficiência. A tela tensionada do edifício em estudo é fixa e constituída de um material diferente das usuais tramas metálicas: segundo o fabricante, a malha é composta de fios de poliéster de alta tenacidade com proteção aos raios ultravioleta. Uma das vantagens deste material é o menor carregamento por $\mathrm{m}^{2}$, o que acarreta em menos elementos de suporte e fixação na fachada.

\subsection{Análise dos Pré-requisitos Gerais}

Como o projeto encontra-se em fase de projeto, não se dispõe de informações quanto ao pré-requisito geral de divisão de circuitos. No caso do pré-requisito geral de aquecimento de água, a edificação usa o mínimo de aquecimento por ser um prédio público.

Além da coleta de dados referentes à forma e dimensões do objeto de estudo, o manual RTQ-C estabelece pré-requisitos para a determinação do nível de eficiência energética da envoltória. São eles: transmitância térmica $(U)$, cores e absortância das superfícies $(q)$, tanto para a cobertura quanto para as paredes externas.

\subsection{Aplicação do RTQ-C - Análise da Envoltória}

Os índices e pré-requisitos foram atendidos para cada nível de eficiência.

\subsubsection{Pré-Requisitos}

Para o cálculo do primeiro pré-requisito, transmitância térmica $(U)$, foram levantados os dados referentes aos materiais das paredes externas e da cobertura, necessários para o cálculo, os quais são apresentados nas Tabelas 22 e 23. Note-se que a transmitância das paredes, uma vez que se adotou a tela tensionada, foi calculada por ponderação de áreas. $O$ valor da transmitância térmica das paredes (Upar) resultante foi de Ucob= 1,30 W/ (m2. K).

A cobertura da ampliação do Edifício Anexo (Figura 3) é composta de diversas camadas que compõem desde o sombreamento da laje até a sua proteção mecânica e impermeabilização. São elas: placas de 
concreto celular autoclavado de $8,5 \mathrm{~cm}$, câmara de ar com $14,5 \mathrm{~cm}$, argamassa comum para proteção mecânica de $6 \mathrm{~cm}$, impermeabilizante, laje de concreto com $30 \mathrm{~cm}$.

Para o cálculo da transmitância da cobertura ainda foram considerados a câmara de ar do entreforro com $52 \mathrm{~cm}$, e o forro de poliestireno expandido moldado de $2 \mathrm{~cm}$. Utilizando-se dos valores para a determinação deste pré-requisito, obtidos através das tabelas A.1, B.1 da NBR 15220 - parte 02 (ABNT, 1992), calculou-se a transmitância térmica da cobertura (Ucob), sendo o valor obtido Ucob= $\mathbf{0 , 5 3} \mathbf{~ W} /$ ( $\mathbf{m} 2$. $\mathrm{K})$.

Desta forma, considerando-se os valores obtidos para parede e cobertura, para o cumprimento dos prérequisitos da Zona Bioclimática 1, verificou-se que o Edifício Anexo atinge no máximo o nível $\mathrm{B}$.

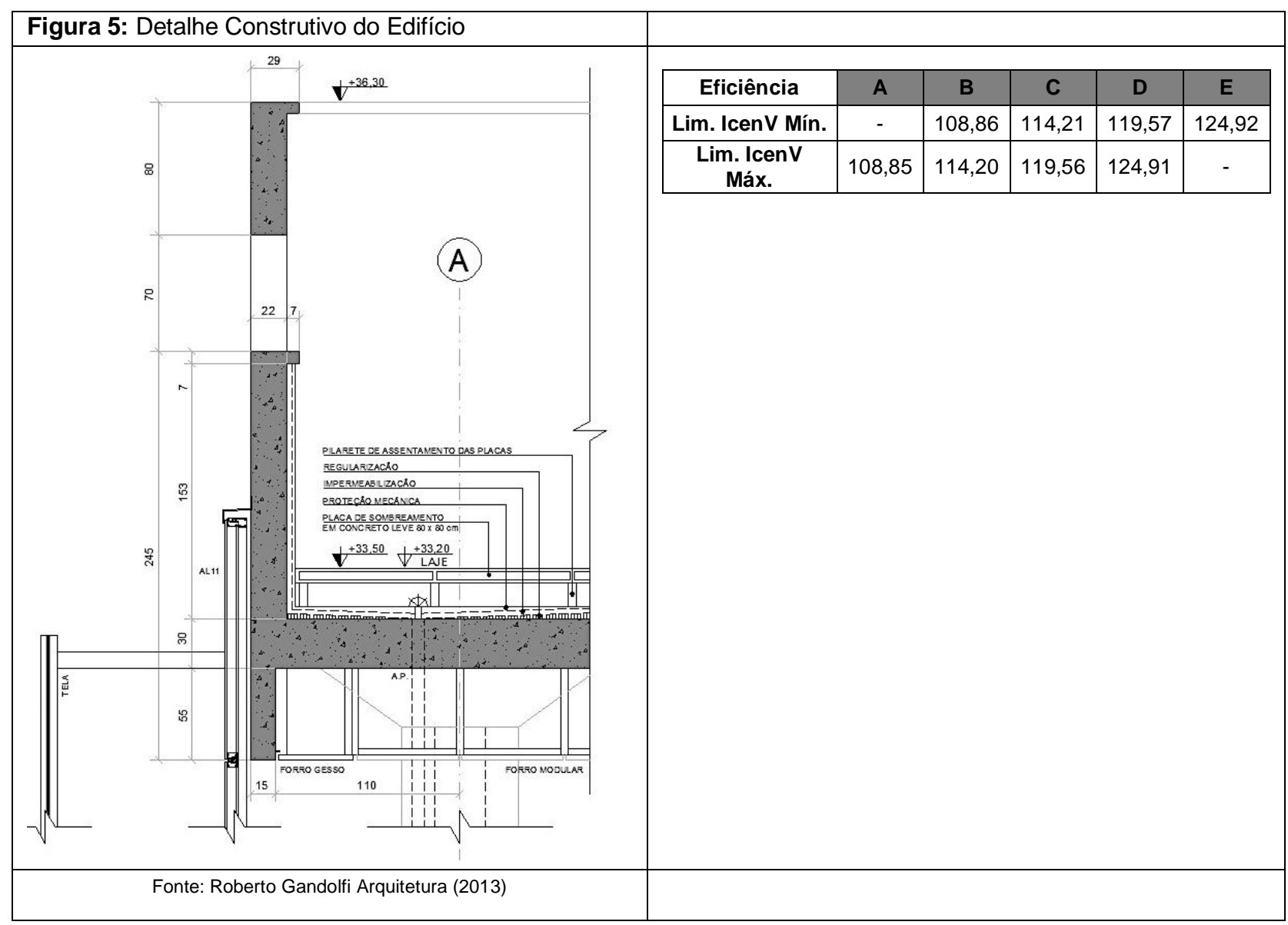

O segundo pré-requisito, cores e absortância de superfícies, não é obrigatório para a Zona Bioclimática 1. O terceiro pré-requisito, iluminação zenital, não é contemplado, não sendo, portanto, atingido.

\subsubsection{Cálculo do Índice de Consumo da envoltória (ICenv) e Classificação pelo RTQ-C}

Após a coleta de todos os dados e a resolução das equações estabelecidas pelo manual RTQ-C, foi obtido o resultado final para o índice de eficiência energética da envoltória do edifício. A Tabela 9 mostra os limites para cada nível. Já a Tabela 15 apresenta o valor final atingido para o índice de consumo, com as variantes do projeto. 
Tabela 9: Limites dos intervalos dos níveis de eficiência.

\begin{tabular}{lcccc}
\hline \multicolumn{1}{r}{ Variável } & Projeto & ICmáxD & Icmín & Intervalo i \\
\hline FA & 0,13 & 0,13 & 0,13 & \\
FF & 0,18 & 0,18 & 0,18 & \\
PAFt & 0,35 & 0,60 & 0,05 & \\
FS & 0,39 & 0,61 & 0,87 & \\
AVS & 0,00 & 0,00 & 0,00 & \\
AHS & 0,00 & 0,00 & 0,00 & \\
ICenv & $\mathbf{1 1 5 , 3 8}$ & 124,91 & 103,50 & 5,35 \\
\hline \multicolumn{5}{c}{ Fonte: Autor } \\
\cline { 2 - 3 }
\end{tabular}

O Nível de Eficiência Energética obtido pelo projeto é o Nível C.

\subsection{Simulações para Otimização da Envoltória com base no RTQ-C}

Foram realizadas simulações com o intuito de otimizar o nível de eficiência energética da envoltória da ampliação do Edifício Anexo, servindo de orientação para o projeto.

\section{Simulação 1: Adição da Tela Tensionada nas Fachadas N e W}

Para esta simulação, propõe-se o uso da tela tensionada em $100 \%$ das fachadas $\mathrm{N}$ e W, diferentemente das outras fachadas que já possuem a tela, porém não em sua totalidade. A Figura 6 ilustra as fachadas que já possuem a tela e a adição do elemento de sombreamento nas fachadas sugeridas.

Figura 6: Simulação 1- Adição da Tela nas Fachadas 4 e 6.

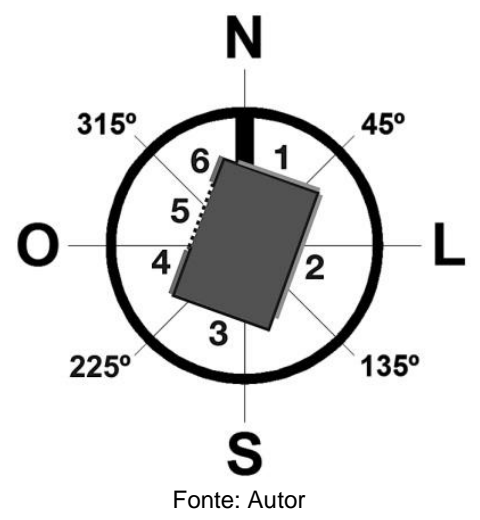

A adição da tela na fachada 4 propõe-se a proteger o edifício da insolação ao final do dia, na orientação oeste. Já o uso da tela na fachada 6 tem por objetivo proteger o edifício da orientação de maior insolação anual, a orientação norte. Como resultado da alteração sugerida, a porcentagem de abertura total das fachadas, antes com $35 \%$, cai para $28 \%$.

A Tabela 10 apresenta o índice final obtido $(112,75)$ com nível final de eficiência energética da envoltória resultante B. Entende-se que, aumentando a proteção das fachadas, antes expostas, é possível aumentar o nível de eficiência energética do edifício. 
Tabela 10: Simulação 1- Adição da tela nas fachadas 4 e 6

\begin{tabular}{lcccc}
\hline Variável & Projeto & ICmáxD & Icmín & Intervalo i \\
\hline FA & 0,13 & 0,13 & 0,13 & \\
FF & 0,18 & 0,18 & 0,18 & \\
PAFt & 0,28 & 0,60 & 0,05 & \\
FS & 0,39 & 0,61 & 0,87 & \\
AVS & 0,00 & 0,00 & 0,00 & \\
AHS & 0,00 & 0,00 & 0,00 & 5,35 \\
\cline { 2 - 3 } IcenV & $\mathbf{1 1 2 , 7 5}$ & 124,91 & 103,50 & \\
\hline \multicolumn{5}{c}{ Fonte: Autor }
\end{tabular}

\section{Simulação 2: Uso da Tela Tensionada com 10\% de Abertura}

A simulação 2 tem por objetivo utilizar o projeto original e as mesmas dimensões da tela, porém a alteração se dá na porcentagem de abertura da mesma. No projeto original, a porcentagem de abertura da tela é de $28 \%$ e para esta simulação propõe-se uma abertura de $10 \%$. Por padrão, o fornecedor não disponibiliza o material com $10 \%$ de abertura, sendo então um projeto especial. Da mesma maneira que a simulação 1, esta diminui a porcentagem de abertura das fachadas. A Tabela 11 apresenta o resultado do índice obtido que se enquadra no nível nível de eficiência da envoltória $\mathbf{B}$.

Tabela 11: Simulação 2 - Tela tensionada com 10\% de abertura

\begin{tabular}{lcccc}
\hline Variável & Projeto & ICmáxD & Icmín & Intervalo i \\
\hline FA & 0,13 & 0,13 & 0,13 & \\
FF & 0,18 & 0,18 & 0,18 & \\
PAFt & 0,31 & 0,60 & 0,05 & \\
FS & 0,39 & 0,61 & 0,87 & \\
AVS & 0,00 & 0,00 & 0,00 & \\
AHS & 0,00 & 0,00 & 0,00 & 5,35 \\
IcenV & $\mathbf{1 1 3 , 8 9}$ & 124,91 & 103,50 & \\
\hline \multicolumn{5}{c}{ Fonte: Autor }
\end{tabular}

Apesar de o nível atingido ser mais alto que o do projeto original, as fachadas NW e SW ainda continuam desprotegidas e o nível de iluminação natural através das telas pode ser afetado, o que pode contribuir negativamente para a produtividade do escritório, influindo no sistema de iluminação (acesso à luz natural).

\section{Simulação 3: Projeto sem Sistema de Sombreamento}

Para se entender a influência da tela tensionada na eficiência energética do edifício, a simulação 3 tem por objetivo analisar o projeto totalmente sem a tela tensionada. Como variação dos cálculos, a porcentagem de abertura das fachadas sobe para $50 \%$. O resultado obtido, conforme apresentado na Tabela 12 foi de 121,32 para o índice de consumo, o que representa a eficiência no nível $\mathbf{D}$. 
Tabela 12: Simulação 3 - Projeto sem sistema de sombreamento

\begin{tabular}{lcccc}
\hline Variável & Projeto & ICmáxD & Icmín & Intervalo i \\
\hline FA & 0,13 & 0,13 & 0,13 & \\
FF & 0,18 & 0,18 & 0,18 & \\
PAFt & 0,50 & 0,60 & 0,05 & \\
FS & 0,39 & 0,61 & 0,87 & \\
AVS & 0,00 & 0,00 & 0,00 & \\
AHS & 0,00 & 0,00 & 0,00 & \\
IcenV & $\mathbf{1 2 1 , 3 2}$ & 124,91 & 103,50 & 5,35 \\
\hline \multicolumn{5}{c}{ Fonte: Autor }
\end{tabular}

Apesar do resultado da simulação sem a tela não ser o mais baixo da escala de níveis, este representou o nível de mais baixa eficiência da envoltória das simulações realizadas. A Tabela 13 apresenta um resumo das simulações, comparativamente ao projeto original.

Tabela 13: Resumo dos níveis de eficiência alcançados

\begin{tabular}{c|c|c|c|c}
\hline \multicolumn{5}{c}{ Quadro Resumo } \\
\hline & Projeto Original & Simulação 1 & Simulação 2 & Simulação 3 \\
\hline Nível de Eficiência & C & B & B & D \\
\hline \multicolumn{7}{c}{ Fonte: Autor }
\end{tabular}

\subsubsection{Alterações no Projeto para o Atingimento do Nível A}

Conforme visto anteriormente, o primeiro passo ainda antes do cálculo do Índice de Consumo da Envoltória (ICenv) é saber se o projeto cumpre os pré-requisitos para a respectiva Zona Bioclimática. Utilizando os mesmos parâmetros pré-definidos para a Zona Bioclimática 1, as sugestões de melhoria são com relação à transmitância térmica da cobertura e das paredes externas.

O valor de transmitância térmica da cobertura para ambientes condicionados para o nível $A$ é de 0,5 $\mathrm{W} / \mathrm{m}^{2} \mathrm{~K}$. Para se alcançar tal índice, propõe-se a adição de uma camada de $10 \mathrm{~mm}$ de isolante térmico EPS ou Poliestireno Expandido. Com a adição desta camada atinge-se o índice pretendido, com 0 resultado de $0,47 \mathrm{~W} / \mathrm{m}^{2} \mathrm{~K}$.

Para o valor da transmitância térmica das paredes externas é preciso atingir o valor $1,0 \mathrm{~W} / \mathrm{m}^{2} \mathrm{~K}$. Para se alcançar o índice, é proposta a substituição dos vidros de $8 \mathrm{~mm}$ com 5,06 W/m²K para outro tipo de envidraçamento, composto de vidro de controle solar $(6 \mathrm{~mm})+\operatorname{Ar}$ seco $(12 \mathrm{~mm})+$ Vidro Laminado incolor (6mm), o que corresponde a 2,8 W/m²K. Utilizando o mesmo método de ponderação para o cálculo no projeto original, obtém-se a transmitância de $0,84 \mathrm{~W} / \mathrm{m}^{2} \mathrm{~K}$.

Com relação ao índice de Consumo, foi utilizada a ferramenta "Atingir Meta" do programa Microsoft Excel onde, inserindo-se o valor adimensional máximo do nível A, 108,85, e tendo como variante a porcentagem de abertura das fachadas, têm-se que para se atingir tal objetivo,o valor do porcentual de abertura na fachada total PAFt deve ser 0,1726 (adimensional).

Em termos de projeto, a busca pelo PAFt menor ou igual 17\% se concentrou na alteração da porcentagem de abertura de todas as fachadas, menos na fachada sul onde é preciso propiciar maior captação de calor no inverno, e parcialmente no segmento de fachada " 5 ", que é a transição com o outro edifício.

Para os segmentos de fachada "1" e "2", sugere-se o uso de tela com abertura de $10 \%$ cobrindo a totalidade dos panos de vidro. Para os segmentos de fachada "4" e "6", sugere-se o uso de empenas cegas, sem aberturas. A Tabela 14 mostra a proposta para o atingimento do PAFt 17,24. 
Tabela 14: Sugestão de alterações das fachadas para se atingir o nível A

\begin{tabular}{|c|c|c|c|c|c|c|}
\hline Elevação & Orientação & $\begin{array}{c}\text { Área total } \\
\left(\mathrm{m}^{2}\right)\end{array}$ & $\begin{array}{l}\text { Área vidros } \\
\text { sem tela }\left(m^{2}\right)\end{array}$ & $\begin{array}{c}\text { Área vidros } \\
\text { através da } \\
\text { tela }(10 \%) \\
\left(\mathrm{m}^{2}\right)\end{array}$ & $\begin{array}{l}\text { Área total } \\
\text { vidros }\left(\mathrm{m}^{2}\right)\end{array}$ & PAF (\%) \\
\hline 1 & Norte & 652,70 & 0,00 & 65,27 & 65,27 & 10,00 \\
\hline 2 & Leste & 939,00 & 0,00 & 93,90 & 93,90 & 10,00 \\
\hline 3 & Sul & 652,70 & 388,80 & 0,00 & 388,80 & 59,57 \\
\hline 4 & Oeste & 322,80 & 0,00 & 0,00 & 0,00 & 0,00 \\
\hline 5 & Oeste & 431,00 & 0,00 & 0,00 & 0,00 & 0,00 \\
\hline 6 & Norte & 181,00 & 0,00 & 0,00 & 0,00 & 0,00 \\
\hline Fachadas $\left(\mathrm{m}^{2}\right)$ & & $3.179,20$ & & & 547,97 & 17,24 \\
\hline
\end{tabular}

As sugestões de projeto estabeleceram modificações referentes ao PAFt pois estão diretamente relacionadas ao uso das telas tensionadas. Entende-se necessário em uma rotina de projeto, após a análise dos dados obtidos pela proposta original, o estudo das outras variantes como o fator de forma e a altura do edifício, com o intuito de se encontrar o melhor equilíbrio entre técnica, função, plástica e eficiência energética.

\section{Conclusões}

Por se tratar de bem tombado, impossibilita-se a alteração de quaisquer aspectos arquitetônicos do Edifício Sede. Sendo assim, os resultados obtidos nas análises do RTQ-C quanto ao sistema da envoltória nesse edifício não são passíveis de melhoria, restando somente possíveis alterações no sistema de iluminação implantado e de condicionamento de ar.

Pelo RTQ-C, tornou-se evidente que existe a necessidade de melhoria do sistema de iluminação artificial existente. Com o intuito de aumentar os níveis de conforto do usuário por meio do aumento da iluminância média dos ambientes, reduzindo-se também o consumo de eletricidade, pode-se atingir um nível mais elevado de eficiência energética, seguindo as especificações descritas no RTQ-C. Para alcançar esta melhoria, uma das alternativas seria a troca dos conjuntos de luminárias existentes para conjuntos mais eficientes com lâmpadas do tipo fluorescente T5 ou, ainda, diminuir a quantidade de luminárias nos ambientes onde a iluminância permite redução até o limite de 500 lux. Para isto, seria necessário um novo projeto luminotécnico, com nova distribuição de luminárias e novas análises de iluminância e potências.

Com relação à ampliação do Edifício Anexo, concluiu-se que a porcentagem de aberturas ou áreas translúcidas no edifício influenciam de maneira significativa os resultados, e que a tela tensionada responde positivamente aos propósitos de alcance de níveis de eficiência. Dos cinco níveis de eficiência, a tela esteve presente nas simulações cujos resultados alcançaram os 3 níveis superiores ( $A, B$ e $C)$. Sem a tela, se obteve o nível $\mathrm{D}$, o mais baixo das simulações.

Entende-se que o aprimoramento do seu estudo formal pode alcançar maiores níveis de eficiência, porém, sugere-se aos projetistas e arquitetos que este aprofundamento técnico não interfira negativamente em outros fatores arquitetônicos, como a função estabelecida ao edifício e seus respectivos índices de iluminação natural e a plástica desejada, que expressa o caráter proposto para a obra arquitetônica.

Demonstra-se também que o estudo de materiais influencia os resultados, como no caso do alcance dos pré-requisitos a serem atendidos antes da análise. Desta forma, se reconhece a importância da compreensão do conceito da envoltória, que não relaciona apenas as fachadas do edifício, mas também sua cobertura. 


\section{Referências}

ABNT. lluminação de ambientes de trabalho - Parte 1I-NBR ISO/CIE 8995-1:2013 Rio de Janeiro. 2013.

ABNT. Desempenho Térmico de Edificações - NBR 15220. Rio de Janeiro. 1992.

ASHRAE/IES. Energy efficient design of new buildings except low-rise residential buildings. ASHRAE/IES 90.1-1989. Illuminating Engineering Society of North America and American Society of Heating, Refrigeration and Air-Conditioning Engineers, Inc. Atlanta, The United States of America, 1989.

BRASIL. Eletrobrás - Procel - Disponível em: http://www.eletrobras.com. 2010. Acessado em: Fevereiro/2012.

BRASIL. Empresa de Pesquisa Energética (EPE)/Ministério Minas e Energia - Balanço Energético Nacional - BEN 2012: Ano base 2011. Rio de Janeiro, 2011. Disponível em https://ben.epe.gov.br/. Acessado em: abril/2013.

BRASIL. Empresa de Pesquisa Energética (EPE)/Ministério Minas e Energia - Balanço Energético Nacional - BEN 2012: Ano base 2012. Rio de Janeiro, 2012. Disponível em https://ben.epe.gov.br/. Acessado em: abril/2014.

BRASIL Anexo da Portaria n. 372/2010 - Requisitos Técnicos da Qualidade para o Nível de Eficiência Energética de Edifícios Comerciais, de Serviços e Públicos. Rio de Janeiro. 2013a.

BRASIL - Procel Info - Centro Brasileiro de Informação de Eficiência Energética. Etiquetagem em Edifícios. (2013b). Disponível em: http://www.procelinfo.com.br/ Acessado em: Novembro/2013.

CARLO, J.C.; LAMBERTS, R. Parâmetros e métodos adotados no regulamento de etiquetagem da eficiência energética de edifícios - parte 1: método prescritivo. Ambiente Construído, Porto Alegre, v. 10, n. 2, p. 7-26, abr./jun. 2010.

FONSECA, I. C. L. da; ALMEIDA, C. C. da R. de; LOMARDO, L. L. B.; MELLO, E. N. Avaliações de conforto ambiental e eficiência energética do projeto do prédio do Centro de Informações do Cresesb, no Rio de Janeiro. Ambiente Construído, Porto Alegre, v. 10, n. 2, p. 41-58, abr./jun. 2010.

FOSSATI, M.; LAMBERTS, R.. Eficiência Energética da Envoltória de Edifícios de Escritórios de Florianópolis: discussões sobre a aplicação do método prescritivo do RTQ-C. Ambiente Construído, Porto Alegre, v. 10, n. 2, p. 59-69, abr./jun. 2010.

GELLER, H. S. Revolução Energética: Políticas para um futuro sustentável. Rio de Janeiro: Relume Dumará: USAid, 2003.

KRÜGER, E.L.; MORI, F. Analise da eficiência energética da envoltória de um projeto padrão de uma agencia bancaria em diferentes zonas bioclimáticas brasileiras. Ambiente Construído, Porto Alegre, $v$. 12, n. 3, p. 89-106, jul./set. 2012.

LAMBERTS, R.; DUTRA, L.; PEREIRA, F. O. R. Eficiência Energética na Arquitetura. PW Editores. São Paulo. 1997.

SILVA, C. J.; SOUZA, J. A.; CANTARINO, M.; MARTINS, C.C.;MACEDO, L.M.; SILVEIRA, M.T.M.; Código Legislativo da Eficiência Energética nos prédio públicos federais. Eletrobrás e Procel EPP - Rio de Janeiro $-2008$.

TRIBUNAL DE CONTAS DO PARANÁ. Acervo técnico. Janeiro/2012. 